Rev Biomed 2003; 14:3.

\title{
La duplicación de artículos en revistas médicas.
}

\section{Editorial}

\author{
Carlos J. Castro-Sansores.
}

Editor Asociado, Revista Biomédica, Universidad Autónoma de Yucatán, Mérida, Yucatán, México.

En el número 2 del volumen 13 de la Revista Biomédica (abril-junio de 2002) se publicó el trabajo “Clínica del Asma: ¿En realidad es útil?” (1). Este mismo trabajo se publicó en la revista Alergia, Asma e Inmunología Pediátricas en el volumen 11 número 2 (mayo-agosto de 2002) (2). El contenido de ambos trabajos, si bien con algunas diferencias de estilo o cambios propuestos por los revisores, es el mismo.

El trabajo fue recibido por la Revista Biomédica el 10 de julio de 2001 y aceptado para su publicación el 18 de octubre del mismo año y aunque la revista de Alergia, Asma e Inmunología Pediátricas no pone en sus artículos cuando fueron recibidos y cuando aceptados, en primera instancia es claro que el trabajo se envió a dos revistas para ser evaluado. En nuestros archivos tenemos la correspondencia donde se le comunica al autor que su trabajo fue aceptado. Del mismo modo, el día 06 de noviembre de 2001 el autor ratifica que su trabajo es inédito y que desea sea publicado en la Revista Biomédica y el 25 de junio de 2002 se le solicitan, para mejorar la calidad de la impresión, nuevamente las 5 figuras de su trabajo ya que el número correspondiente de la Revista se encuentra en prensa.

Aunque en los instructivos de autores de ambas revistas se especifica que los artículos deben de ser originales y no deben de encontrarse evaluando en otra revista de acuerdo a las normas internacionales de revistas médicas (3), claramente se puede corroborar que este criterio no se cumplió.

Mas allá de los aspectos éticos, las publicaciones duplicadas crean confusión en la búsqueda de información, restan espacio para la publicación de otros trabajos, se crean registros dobles en las bases de datos médicas, incrementan falsamente el currículum del autor y violan la ley del derecho de autor.

Por fortuna no es éste un hecho frecuente, sin embargo quizá sea el momento para poner a debate ante la Asociación Mexicana de Editores de Revistas Biomédicas A.C. (AMERBAC), acciones más enérgicas contra los autores que incurran en este hecho.

\section{REFERENCIAS.}

1.- Lara-Pérez EA. Clínica del asma: ¿en realidad es útil? Rev Biomed 2002; 13: 84-92.

2.- Lara-Pérez EA. Clínica del asma: ¿en realidad es útil? Alergia Inmunol Ped 2002; 11: 41-7.

3.- International Committee of Medical Journal Editors. Uniform requirements for manuscripts submitted to biomedical journals. N Engl J Med 1997; 336: 309-15. 